\title{
O PAPEL DO TEXTO NA COMPREENSIBILIDADE DE E-SERVIÇOS
}

\section{THE ROLE OF TEXT IN THE COMPREHENSIBILITY OF E-SERVICES}

\author{
Heloisa Fischer ${ }^{1}$, Mestranda \\ Claudia Mont'Alvão ${ }^{2}$, D.Sc. \\ Erica dos Santos Rodrigues ${ }^{3}$, D.Sc.
}

(1) PUC-Rio PPGDesign/ Laboratório de Ergodesign e Usabilidade de Interfaces (LEUI)

helofischer@gmail.com

(2) PUC-Rio PPGDesign/ Laboratório de Ergodesign e Usabilidade de Interfaces (LEUI) cmontalvao@puc-rio.br

(3) PUC-Rio PPG Estudos da Linguagem/ Laboratório de Psicolinguística e Aquisição de Linguagem

(LAPAL)

ericasr@puc-rio.br

Governo eletrônico, Compreensibilidade textual, Linguagem Simples

Este artigo discute o papel da compreensibilidade textual no acesso a serviços públicos digitais brasileiros, apresentando resultados parciais de pesquisa documental e revisão bibliográfica. O trabalho aborda os conceitos de interação em governo eletrônico, valor público (relacionado ao design do e-serviço), burocratês e Linguagem Simples. Também exemplifica aspectos linguísticos do burocratês a partir de um fragmento de texto de e-serviço do governo federal.

\section{E-Government; Textual comprehensibility; Plain Language}

This article discusses the role of textual comprehensibility in accessing Brazilian digital public services. It reports partial results of documental research and literature review. The paper addresses the concepts of interaction in e-government, public value (related to e-services design), officialese, and Plain Language. It illustrates the linguistic aspects of the officialese from a fragment of e-service text from the federal government.

\section{Introdução}

Um dos desafios atuais da transformação digital do setor público é facilitar o acesso a serviços em governo eletrônico (BRASIL, 2018b, p.24; UNITED NATIONS, 2018, p.30). Entende-se por governo eletrônico, ou e-gov, o uso das tecnologias de informação e comunicação na administração pública (COMITÊ, 2018, p.98).

Neste contexto, a interação dos cidadãos ocorre em plataformas digitais e os serviços públicos passam a ser chamados de "e-serviços".

Muitos países enfrentam baixos níveis de adoção de e-serviços pelos usuários (RANA E DWIVEDI, 2015). No Brasil, os e-serviços federais atendem oito categorias de usuários: cidadãos e famílias; estrangeiros(as); empresas privadas; empresas públicas ou de economia mista; pessoas jurídicas de direito privado sem fins lucrativos; fundações e autarquias de direito privado; órgãos da administração direta; estados e municípios. (BRASIL, 2018).

Estudos sobre a facilitação de acesso a e-serviços indicam diferentes alternativas. Há os que consideram prioritário atender as expectativas que os cidadãos têm ao interagir com a governança digital. Tal perspectiva vem sendo defendida em trabalhos recentes sobre valor público (ALHURJAN ET AL., 2015; LOPES, 2016; LOPES, LUCIANO E MACADAR 2018a e 2018b; JORDAN, 2019).

Nesses trabalhos, o design do e-serviço é apontado como um dos fatores direcionadores de valor público. Projetar e-serviços orientados aos usuários, 
facilitando o acesso e entregando conveniência, constitui uma das formas de governos criarem valor público.

Apesar de ser essencial para a compreensão dos eserviços, o texto não vem recebendo espaço nas pesquisas sobre criação e percepção de valor público. Mas a informação escrita é um elemento básico na prestação de qualquer serviço público, especialmente em meio digital.

Textos de e-serviços - assim como os textos de governo eletrônico e os da comunicação pública em geral - costumam ser redigidos em um estilo que é dicionarizado no português brasileiro como "burocratês" (HOUAISS, 2001, pag. 532). Trata-se de uma escrita que diverge do tipo de linguagem que é familiar aos usuários.

A técnica de comunicação globalmente conhecida como Plain Language (Linguagem Simples) oferece um contraponto à redação em burocratês. Ela vem sendo construída por diversos atores sociais internacionais - especialmente os atuantes no setor público - ao longo de várias décadas. A Linguagem Simples é uma técnica para elaborar textos claros, concisos e objetivos e um movimento que defende o direito de entender as informações de interesse público.

A técnica da Linguagem Simples privilegia um vocabulário familiar ao cidadão comum e recomenda, entre outros aspectos, a construção de frases estruturalmente menos complexas, fáceis de ler. Vem sendo usada no governo eletrônico de alguns países, como Reino Unido e Estados Unidos, mas ainda é incipiente no processo de digitalização de governos no Brasil (FISCHER, 2018).

O objetivo deste artigo é discutir como a compreensibilidade textual pode contribuir para a facilitação de acesso a serviços públicos digitais brasileiros. Para tal, parte dos conceitos de interação em e-gov, valor público, burocratês e Linguagem Simples.

O trabalho está organizado da seguinte forma. A seção 2 discute o estágio de digitalização de serviços públicos do governo federal brasileiro, a ideia de barreiras para interagir em e-gov e o conceito de valor público, enfatizando o design do e-serviço.
A seção 3 é dedicada ao estilo textual em governo eletrônico. Apresenta os aspectos linguísticos do burocratês, exemplifica o seu impacto na compreensibilidade textual com um fragmento de texto sobre um serviço disponível no portal gov.br. Apresenta características da Linguagem Simples, indica os países que utilizam a técnica em textos de e-gov e aponta as iniciativas no setor público brasileiro.

$\mathrm{O}$ artigo termina com uma breve síntese da discussão aqui proposta e sinaliza os próximos passos da pesquisa no mestrado do programa de Pós-Graduação em Design na PUC-Rio que embasou este artigo.

2. Digitalização de serviços públicos, barreiras à interação e valor público

2.1. Estágio de digitalização dos serviços públicos federais

Em 2020, o processo de digitalização da administração pública federal brasileira completa duas décadas (BRASIL, 2000 a). O período acumula marcos regulatórios, padrões normativos, desenvolvimento de plataformas e pesquisas de avaliação, entre outras ações.

O conjunto de esforços mostra resultado. A mais recente edição do Índice de Desenvolvimento de Egov, feito pela $\mathrm{ONU}$, coloca o Brasil na $44^{\mathrm{a}}$ posição entre os 193 países-membro da entidade (UNITED NATIONS, 2018). Na edição anterior, dois anos antes, o país ocupava o $51^{\circ}$ lugar.

A maioria dos serviços públicos no Brasil é fornecida por estados e municípios (OECD, 2018, p. 22). Ainda assim, os serviços prestados em nível federal são bastante significativos. Por ocasião da elaboração deste artigo, em fevereiro de 2020, o site gov.br agregava um total de 3.444 serviços em 185 órgãos federais (Figura 1). 
Figura 1: Painel de monitoramento de serviços

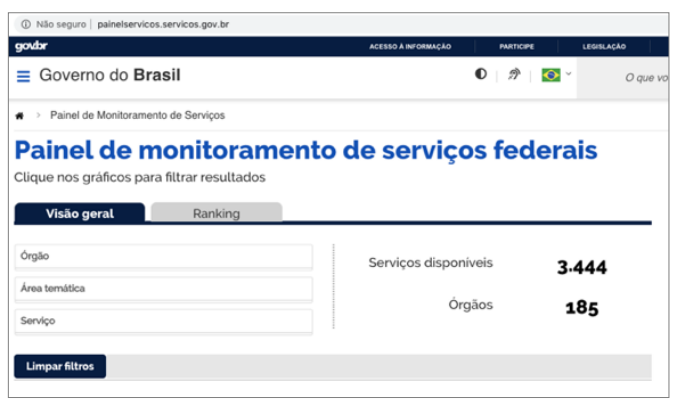

\section{Fonte: Portal GOV.BR ${ }^{1}$}

A facilitação de acesso a serviços digitais é um dos principais desafios para aprimorar a efetividade das ações de e-gov em âmbito federal (BRASIL, 2018b, p.24).

Uma pesquisa da Escola Nacional de Administração Pública (Enap) categorizou cinco estágios de digitalização dos serviços e indicou os seus respectivos percentuais ${ }^{2}$ :

- Nenhum (15,6\%): Totalmente prestado por presença física, sem disponibilizar informações em plataformas digitais;

- Informativo (8,8\%): Acesso a informações sobre o serviço em plataformas digitais. A prestação é totalmente presencial;

- Parcial (44,1\%): Pelo menos uma etapa do processo de atendimento ocorre por meio digital;

- Digital (24\%): Todas as interações são realizadas por meio digital, mas requer alguma ação humana por parte do órgão;

- Autosserviço (7,4\%): Completamente automatizado. Todo processamento é realizado por sistemas de informação (BRASIL, 2018a, p.64).

\section{A Política Brasileira de Governança Digital} determina o autosserviço como a forma prioritária de prestação de serviços públicos em meio digital (BRASIL, 2016a).

Ou seja, a meta do e-gov federal é fazer com que o maior número possível de serviços seja acessado

\footnotetext{
${ }^{1}$ Imagem capturada em 29/09/2020.

${ }^{2}$ A pesquisa da Enap analisou 1.740 serviços de 85 órgãos federais.
}

sem requerer qualquer tipo de intermediação humana. Os percentuais aferidos pela pesquisa da Enap mostram que e-serviços com completa automatização ainda são a minoria, apesar de serem uma prioridade administrativa.

\subsection{Facilitação de acesso a e-serviços e compreensibilidade textual}

Se no autosserviço a possibilidade de esclarecer dúvidas por meio de interações humanas é totalmente eliminada, nos demais estágios de digitalização - informativo, parcial e digital -, as chances de o usuário receber explicação pessoal para as suas indagações são cada vez mais reduzidas ou tendem a desaparecer. Esta conjuntura imprime a necessidade de escrever informações e instruções sobre e-serviços de modo a minimizar as dúvidas.

Apesar disso, os textos governamentais continuam sendo redigidos no estilo de escrita típico da burocracia pública, só compreensível por técnicos e especialistas. Escrever informações e instruções sobre e-serviços de forma clara, concisa e objetiva, em um linguajar familiar aos cidadãos, com palavras que qualquer leitor conheça, requer uma mudança estrutural na comunicação pública.

Neste sentido, estudos sobre facilitação de acesso a e-serviços vêm incentivando os governos a realizarem transformações com vistas a atender melhor a população.

A Estratégia de Governança Digital observa que o principal desafio da transformação digital de governos não é tecnológico, consistindo em vez disso em "direcionar esforços e coordenar mudanças estruturais na organização da sociedade e do governo" (BRASIL 2018b, p.5, grifo das autoras).

O estudo "Revisão do Governo Digital do Brasil", conduzido pela Organização para a Cooperação e Desenvolvimento Econômico (OCDE), reiterou a importância de a governança brasileira mudar a orientação e ir ao encontro das necessidades do usuário de e-serviços:

A realização da priorização de uma sólida política de entrega de serviços digitais permitirá ao governo brasileiro mudar o panorama do país e deixar gradativamente de ser centrado nas instituições e em suas práticas para que a prestação de serviços seja orientada ao usuário (OECD, 2018, p.22, grifo das autoras). 
PUC-Rio Pontifícia Universidade Católica do Rio de Janeiro Departamento de Artes \& Design | PPGDesign

Já a pesquisa da Escola Nacional de Administração Pública sobre serviços públicos prestados pelo governo federal concluiu o seguinte:

A partir dos dados levantados nesta pesquisa, podese inferir que uma política pública de construção do e-government, no Brasil, deve dar conta de um processo complexo que respeite um fluxo orientado à prestação de serviços para a cidadania, ao mesmo tempo em que mude a estrutura das burocracias e os modelos de gestão pública. (BRASIL, 2018a, p.75, grifo das autoras)

A necessidade de facilitar o acesso a serviços públicos digitais parece fornecer condições para que o estilo de texto em e-gov passe a priorizar as necessidades dos usuários.

\subsection{Barreira linguística à interação em e-gov}

Barreiras à interação em e-gov são um problema global e multifacetado que agrava a segregação digital (digital divide) em todos os países.

Inicialmente, a segregação digital era relacionada à falta de acesso à internet e a computadores. Com o passar do tempo, o avanço da tecnologia trouxe outros agravantes da segregação, como a velocidade de conexão, a qualidade dos equipamentos e o conhecimento sobre como usá-los.

A Organização das Nações Unidas esquematiza treze tipos de barreira que dificultam o acesso a eserviços e afetam a participação cidadã (UNITED NATIONS, 2018, p.34).

A lista inclui barreiras geográficas, por localização em áreas rurais ou remotas com qualidade de conexão ruim; barreiras de idade, sendo os idosos a faixa etária mais prejudicada pela falta de competências digitais; e até as barreiras de conteúdo, levando em conta os países que têm idiomas locais e só disponibilizam os seus eserviços na língua oficial.

A ONU considera a sua categorização de barreiras agravadoras da segregação digital apenas um apanhado inicial. Por conseguinte, estimula a comunidade internacional a expandi-lo.

Nesse sentido, poderia ser possível considerar a linguagem burocrática usada pelo setor público como uma barreira à interação em e-gov e um agravante da segregação digital. Por prejudicar a compreensão textual sobre os e-serviços, o burocratês compromete-lhes o acesso e afeta o pleno exercício da cidadania.

$\mathrm{Na}$ medida em que a ONU recomenda que governos comprometam-se a disponibilizar serviços públicos 'a todos, sem deixar ninguém para trás' (UNITED NATIONS, 2018, xxiii), cabem ser consideradas ações que atenuem as barreiras de compreensão textual impostas pelo burocratês.

Lopes, Macadar e Luciano (2018b) advertem que 'inovação em governo só faz sentido se entrega valor às pessoas'. Como veremos na seção 3 , a adoção de um estilo de escrita orientado pelas diretrizes do Movimento Plain Language, pode ser um caminho nessa direção.

\subsection{Valor público e design de e-serviços}

Valor público foi um termo cunhado na área de administração pelo pesquisador americano Mark Moore, da Universidade de Harvard, em 1995. À época, a perspectiva New Public Management (NPM) promovia a ideia de gerir governos como empresas privadas: terceirizar e privatizar, reduzir custo e pessoal, transformar servidores públicos em gerentes e encarar os cidadãos como clientes.

Moore introduziu o conceito de valor público como contraponto à NPM, promovendo a ideia de que gestores públicos deveriam procurar produzir valor público (JORDAN, 2019).

Lopes, Luciano e Macadar (2018a) realizaram uma análise bibliométrica da produção científica sobre valor público e concluíram que o conceito conectouse à pauta de governo digital a partir de 2003, com um aumento significativo de publicações a partir de 2015. Mas as pesquisas ainda são poucas, especialmente no Brasil.

Por não existir uma definição canônica do termo, as pesquisadoras brasileiras analisaram definições presentes em vinte trabalhos internacionais e propuseram o seguinte conceito: "Valor público é o valor produzido pelo governo, que é percebido pelos cidadãos e criado na adoção dos serviços digitais" (p. 216).

A conceituação de Kelly et a.l (2002), ponto de partida do artigo mais citado pelo levantamento bibliométrico e referência recorrente em muitas 
publicações sobre o tema, enfatiza o papel central que cabe ao cidadão:

Valor público refere-se ao valor criado pelo governo através de serviços, legislação e outras ações. Numa democracia, este valor é definido em última instância pelo próprio público. $\mathrm{O}$ valor é determinado pelas preferências dos cidadãos, expressas em uma variedade de meios e refletidas nas decisões dos políticos eleitos. [...] Como regra geral, o que mais os cidadãos valorizam tende a se encaixar em três categorias: resultados, serviços e confiança (KELLY ET AL. 2002, p. 4 , tradução das autoras $)^{3}$

Considerando a baixa adoção de e-serviços por cidadãos, Al-Hujran et al. (2015, p. 189) frisam "a importância de compreender os variados fatores que podem influenciar a adoção de serviços digitais por parte dos cidadãos". Este ponto de vista é corroborado por Lopes:

Os governos devem aumentar a conscientização dos cidadãos sobre o valor do uso dos e-serviços e melhorá-los à luz das necessidades dos cidadãos. Assim, a compreensão dos fatores que influenciam a adoção dos e-serviços pelos cidadãos passa a ser uma questão política relevante e deve estimular a ampliação do conhecimento nesse domínio para elaboração de políticas públicas e como insumo para melhoria do design dos e-serviços (LOPES, 2016, p.57).

O estudo de Lopes (2016) categorizou quatro fatores direcionadores para criação de valor público em eserviços: processo colaborativo, design do e-serviço, abertura governamental e confiança dos cidadãos.

Por design do e-serviço, a autora entende "os aspectos relacionados ao projeto, concepção e desenho até a sua efetiva prestação do e-serviço, na perspectiva do cidadão".

\footnotetext{
${ }^{3}$ No original em inglês: "Public value refers to the value created by government through services, laws, regulation and other actions. In a democracy this value is ultimately defined by the public themselves. Value is determined by citizens' preferences, expressed through a variety of means and refracted through the decisions of elected politicians. [...] As a general rule the key things which citizens value tend to fall into three categories: outcomes, services and trust."
}

Em trabalho posterior, decorrente da mesma pesquisa, Lopes, Luciano e Macadar (2018b) elencaram as seguintes variáveis observáveis no design do e-serviço: orientação para o usuário, facilidade de uso e usabilidade.

Em relação à facilidade de uso, Al-Hujran et al. concluíram que:

O valor público percebido e a facilidade de uso percebida mostraram-se determinantes das atitudes dos cidadãos em relação ao uso de serviços de governo eletrônico, sugerindo que o governo deveria tornar os governos eletrônicos mais valiosos e usáveis (ALHUJRAN ET AL., 2015, p. 198, tradução das autoras $)^{4}$

Tendo em conta que e-serviços são acessados a partir de informações e instruções escritas nas interfaces digitais, pode-se entender que o atributo "facilidade de uso" abarca o texto. Mas os trabalhos aqui citados não mencionam aspectos textuais associados à facilidade de uso.

A próxima seção discutirá o estilo textual em e-gov, considerando as características linguísticas do burocratês e da aplicação da Linguagem Simples em governos eletrônicos.

\section{O estilo textual em e-gov}

\subsection{Características linguísticas do burocratês}

Na maioria dos países, inclusive no Brasil, textos em e-gov costumam seguir o mesmo padrão de linguagem burocrática característico da comunicação pública.

O burocratês é marcado pela escrita floreada, herdeira da linguagem jurídica, com estrutura sintática complexa, pseudoerudita, vocabulário pouco familiar e alta carga informacional. De tão complexo e obscuro, este estilo de redação foi classificado como "obscuranto" em documentos oficiais da União Europeia e tornou-se verbete do dicionário Bloomsbury Business \& Management.

4 No original em inglês: "Perceived public value and perceived ease of use were shown to be significant determinants of citizen's attitudes toward using egovernment services, suggesting that the government should make e-governments more valuable and usable." 
PUC-Rio Pontifícia Universidade Católica do Rio de Janeiro Departamento de Artes \& Design | PPGDesign

LEUI | Laboratório de Ergodesign e Usabilidade de Interfaces

Em um estudo pioneiro nos anos 1980, Neide Rodrigues de Souza Mendonça assim definiu o estilo:

A linguagem burocrática - burocratês, prosa institucional ou linguagem da burocracia - é uma subvariedade escrita da língua materna, usada pelos membros da administração durante o seu trabalho. É encontrada nos documentos que emanam das instituições públicas (municipais, estaduais e federais) e privadas. [...] O psicolinguista Frank Smith afirma que, algumas vezes, a linguagem usada por médicos, advogados e burocratas é de difícil compreensão e que essa incompreensibilidade é voluntariamente criada." (MENDONÇA, 1987, p. 11)

Mendonça acrescenta que os traços específicos do burocratês "podem ser evidenciados no léxico e em construções gramaticais especiais" (ibidem, p. 12).

Maria Inês Matoso Silveira observa que o uso de fórmulas arcaicas e empoladas "faz o burocratês parecer uma linguagem para iniciados, de caráter excludente". E adverte para os problemas que causa à compreensibilidade dos textos:

De fato, além do uso de terminologias técnicas específicas, a linguagem burocrática, quando revestida de suas tradicionais características estilísticas, se transforma em um sério problema de compreensão para as pessoas externas às suas comunidades discursivas, ou seja, para as pessoas que não estão diretamente ligadas aos setores da burocracia administrativa em instituições públicas e particulares. (SILVEIRA, 2008, p. 224)

Para Silveira (2008), a formalidade e a impessoalidade são as principais marcas linguísticas do burocratês. A formalidade expressa-se na escolha de vocativos, pronomes de tratamento, fórmulas de polidez, fórmulas de saudação e rebuscamento de vocabulário, com eufemismos, termos abstratos, jargão burocrático e arcaísmo. A impessoalidade expressa-se principalmente no uso de voz passiva, nominalizações e o evitamento da referência anafórica pronominal.

Trabalhos anteriores já problematizaram o burocratês na governança digital brasileira, recomendando a Linguagem Simples (BARBOSA e NUNES, 2007; BARBOZA, 2010). Também já foi avaliada a compreensibilidade textual em e-gov antes e depois da reescrita em Linguagem Simples, usando o Teste de Cloze (MARTINS e FILGUEIRAS, 2007).

À constatação dos pesquisadores aqui reunidos, sobre o burocratês ser inacessível à maioria dos cidadãos brasileiros, acrescentem-se os dados de alfabetismo no país. Os números a seguir constam do relatório INAF Brasil 2018- Indicador de Alfabetismo Funcional. O estudo mediu os níveis de alfabetismo da população brasileira de 15 a 64 anos:

- $\quad \mathbf{2 9} \%$ de analfabetos funcionais: não sabem ler (analfabetos) ou só localizam informações explícitas e literais, em textos muito simples (nível rudimentar);

- $\quad 34 \%$ em nível de alfabetismo elementar: sob certas condições, selecionam informações em textos de extensão média e fazem pequenas inferências;

- $25 \%$ em nível de alfabetismo intermediário: localizam informação expressa de forma literal e realizam pequenas inferências;

- $\quad 12 \%$ em nível de alfabetismo proficiente: elaboram textos de maior complexidade (AÇÃO EDUCATIVA, 2018).

A Figura 2 exemplifica o tipo de dificuldade que o burocratês coloca à compreensibilidade de informações sobre serviços públicos.

Figura 2 - Serviço "Aquisição de repelente"

Fonte: Portal GOV.BR ${ }^{5}$

Trata-se de um fragmento do texto informativo sobre o serviço "Aquisição de repelente para gestante inscrita no programa Bolsa Família", disponível no portal gov.br. Neste serviço do governo federal, os usuários são prefeituras.

${ }^{5}$ Disponível em https://www.gov.br/pt$\mathrm{br} /$ servicos/adquirir-repelente-para-gestante-inscritano-programa-bolsa-familia 
O fragmento é composto por uma única sentença de 73 palavras, muito acima do número médio de 15/20 palavras, a partir do qual as diretrizes internacionais de Linguagem Simples recomendam reescrever o período. ${ }^{6}$

O sujeito, que tem como núcleo "aquisição e distribuição", é longo e modificado por sintagmas sucessivos e encadeados, implicando alto custo para a memória de trabalho. Inclui ainda o uso de uma forma reduzida de passiva ("realizada pelo Ministério da Saúde") e termina com uma referência extratextual à lei que fundamenta o referido benefício.

$\mathrm{O}$ objeto direto oracional (iniciado por "oferecer às gestantes...") também se caracteriza pela longa extensão e por envolver formas passivas ("transmitidas" e "relacionadas"). O uso de palavras pouco conhecidas também chama a atenção, com destaque para os termos "arborivoses", "microcefalia" e "nascituros".

\subsection{Linguagem Simples (Plain Language): características da técnica}

Linguagem Simples (Plain Language) é uma técnica de comunicação e um movimento social com força em vários países. Também é conhecida em português como linguagem clara - especialmente em Portugal - ou linguagem cidadã.

Como causa social, é um movimento internacional que mobiliza diversos atores sociais na defesa do direito de entender os textos de interesse público (FISCHER, 2018). Como técnica de comunicação, a linguagem Simples segue uma série de diretrizes de redação, design da informação e usabilidade para facilitar a leitura de textos (SCHRIVER, 2017).

\footnotetext{
${ }^{6}$ É importante observar que o número de palavras do período não deve ser dissociado de fatores linguísticos que podem tornar o texto complexo do ponto de vista de seu processamento. Um texto de 20 palavras pode ser mais complexo do que um de 40, por exemplo, a depender das escolhas lexicais e sintáticas. Soma-se a essa discussão o fato de as línguas apresentarem recursos estruturais distintos e qualquer discussão sobre complexidade linguística não pode desconsiderar esse aspecto. Conforme será apontado na seção seguinte, Cutts (2013) sugere a média de 15/20 palavras. Esta recomendação baseia-se em um estudo de corpus para a língua inglesa realizado no final dos anos 1960 por Kucera e Francis (ANDERSON, 1971).
}

O site da Plain Language Association

International-PLAIN (Associação Internacional de Linguagem Clara-PLAIN), entidade com sede no Canadá, oferece a seguinte definição, já em português:

Uma comunicação está em linguagem clara quando o texto, a estrutura e o design são tão claros que o público-alvo consegue encontrar facilmente o que procura, compreender o que encontrou e usar essa informação. Usar linguagem clara significa priorizar o leitor. Descobrir o que os leitores querem saber, de que informação precisam, e ajudá-los a alcançar suas metas. O objetivo é que o leitor consiga compreender um documento escrito em linguagem clara logo na primeira leitura. Mas linguagem clara não é só uma questão de linguagem. Também inclui design, diagramação e muito mais." (PLAIN, [s.d.] - grifo das autoras)

A centralidade que a Linguagem Simples atribui ao papel do leitor está em sintonia com o atributo "orientação ao usuário", que embasa o referencial teórico sobre valor público e, especificamente, em sintonia com o fator direcionador "design do eserviço: facilidade de uso".

Quanto às características da redação em Linguagem Simples, Cutts (2013) propõe o uso de 25 diretrizes. Harris, Kleinman e Mowat (2010) sintetizaram o trabalho de Cutts em doze diretrizes, assim agrupadas:

\section{Estilo e gramática}

1. Escreva frases com extensão média de 15 a 20 palavras.

2. Use palavras que o leitor provavelmente entenderá.

3. Use apenas o número necessário de palavras.

4. Prefira a voz ativa, a menos que tenha uma boa razão para usar a passiva.

5. Use verbos claros e vívidos para expressar ações.

6. Divida o texto em tópicos.

7. Apresente seu assunto de modo claro e categórico sempre que possível.

8. Reduza ao mínimo as referências extratextuais.

9. Evite linguagem com marcadores de gênero.

10. Seja preciso na pontuação.

\section{Organização}

11. Organize seu material de modo a ajudar o leitor a captar rapidamente as informações importantes e a se orientar com facilidade pelo texto. 


\section{Diagramação}

12. Dê às suas palavras uma apresentação visual clara e acessível.7

Pode-se concluir que a redação em Linguagem Simples tem potencial para minimizar os problemas de compreensibilidade textual decorrentes do uso do burocratês em informações sobre serviços públicos digitais. Também pode-se inferir que existe uma paridade entre esta técnica de comunicação e os fatores direcionadores de valor público.

\subsection{O uso de Linguagem Simples em e-gov no mundo e no Brasil}

Há registros de uso de Plain Language na administração pública dos Estados Unidos e do Reino Unido já nos anos 1940, em grande parte por iniciativa própria dos servidores (GOBBLEDYGOOK, 1944; GOWERS, 1988).

A partir dos anos 1970, o movimento expandiu-se para outros países. Dos anos 2000 em diante, a transformação digital de governos impulsionou o uso da Linguagem Simples mesmo em países com população altamente escolarizada (FISCHER, 2018, p. 21-36)

Atualmente, há pelo menos cinco países que disponibilizam na internet as suas diretrizes oficiais para uso de Linguagem Simples em e-gov. São eles Estados Unidos, Reino Unido, Canadá, Austrália e Nova Zelândia.

As diretrizes para escrita em Linguagem Simples de cada país estão listadas nos seguintes endereços:

\footnotetext{
${ }^{7}$ No original em inglês: Style and grammar: Make the average sentence length of 15-20 words; Use words your reader is likely to understand; Use only as many words as you need: Prefer the active voice unless there's a good reason for using the passive; Use clear, lively verbs to express actions; Use vertical lists to break up text; Put your points positively when you can; Reduce cross references to a minimum; Avoid sexist usage; Use accurate punctuation. Organisation: Organise your material in a way that helps the reader to grasp the important information early and to navigate through the document easily. Layout: Use clear layout to present your words in an easily accessible way.
}

- Estados Unidos: plainlanguage.gov/guidelines/

- Reino Unido: gov.uk/guidance/contentdesign/writing-for-gov-uk

- Canadá: canada.ca/en/treasury-boardsecretariat/services/governmentcommunications/canada-content-styleguide.html\#toc6

- Austrália: guides.service.gov.au/contentguide/writing-style/

- Nova Zelândia: digital.govt.nz/standardsand-guidance/design-and-ux/contentdesign-and-management/plain-language/

No Brasil, existem leis que determinam informação clara e fácil de entender na comunicação com os cidadãos (BRASIL, 2011; BRASIL, 2015; BRASIL, 2017; BRASIL, 2018). Ainda assim, políticas de governo voltadas ao uso de Linguagem Simples na comunicação pública só passaram a existir a partir de 2019. Antes disso, houve poucas iniciativas de órgãos públicos em torno do tema.

No ano de 2016, foram lançadas uma cartilha que problematizou o burocratês e uma publicação com orientações para uso de Linguagem Simples na abertura de dados governamentais.

O Ministério do Planejamento, Desenvolvimento e Gestão lançou a cartilha "Fugindo do 'burocratês': como facilitar o acesso do cidadão ao serviço público" (BRASIL, 2016b). Esta cartilha fez parte do programa GesPública-Programa Nacional de Gestão Pública e Desburocratização.

Já a Secretaria de Governo e a Casa Civil do governo estadual de São Paulo publicaram o guia "Orientações para adoção de linguagem clara" (SÃO PAULO, 2016). A publicação foi produzida pela Fundação Sistema Estadual de Análise de Dados - Seade no âmbito de um projeto em cooperação com o governo do Reino Unido chamado SPUK (o nome do projeto é uma junção das siglas SP e UK). O objetivo era fomentar boas práticas na abertura de dados governamentais.

Nenhuma das iniciativas lançadas em 2016 teve desdobramentos significativos. O GesPública foi extinto em 2017 e, até a data em que este artigo foi elaborado, o portal Governo Aberto SP não havia assimilado as diretrizes produzidas pela Fundação Seade. 
PUC-Rio Pontifícia Universidade Católica do Rio de Janeiro Departamento de Artes \& Design | PPGDesign

A partir de 2018, o tema da Linguagem Simples ganhou espaço em eventos sobre e-gov. Em dezembro daquele ano, o III Encontro Brasileiro de Governo Aberto, em São Paulo promoveu o painel "Só é acessível se der para entender: linguagem clara já!” (III ENCONTRO, 2018).

Em 2019, a Linguagem Simples foi inserida na programação do Encontro Internacional de Inovação em Governo, em agosto (ENCONTRO, 2019). O encontro foi organizado pela Secretaria Municipal de Inovação e Tecnologia de São Paulo. O tema também ocupou a programação da $5^{\mathrm{a}}$ Semana de Inovação em Gestão Pública, em novembro, que foi organizada em Brasília pelo Ministério da Economia, Escola Nacional de Administração Pública, Tribunal de Contas da União e Flacso Brasil (5 SEMANA, 2019). Lá, a Linguagem Simples foi discutida na sessão "Tendências em Experiência do Usuário".

O ano de 2019 viu surgir a formatação de políticas públicas voltadas a implementar o uso de Linguagem Simples nos âmbitos federal e municipal.

Em abril de 2019, foi proposto na Câmara Municipal de São Paulo um projeto de lei para instituir a Política Municipal de Linguagem Clara (SÃO PAULO, 2019). Por ocasião da elaboração deste artigo, o projeto de lei já tinha sido aprovado em plenário com alteração de nome - passando a usar o termo Linguagem Simples - e aguardava a sanção do prefeito.

Em novembro de 2019, o poder executivo municipal de São Paulo lançou o Programa Municipal de Linguagem Simples, por meio de um decreto (SÃO PAULO, 2019). O programa está sendo implementado pelo laboratório de inovação (011).lab, um órgão da Secretaria Municipal de Inovação e Tecnologia.

Em dezembro de 2019, foi apresentado na Câmara dos Deputados um projeto de lei nos mesmos moldes do já aprovado pelo legislativo municipal paulistano (BRASIL, 2019). Por ocasião da elaboração deste artigo, a tramitação na Câmara dos Deputados estava em curso.

\section{Conclusão e próximos passos}

Este artigo discutiu como a compreensibilidade textual pode contribuir para facilitar o acesso a e- serviços, para mitigar as barreiras à interação em egov, e também para a criação e percepção de valor público na governança digital brasileira.

O trabalho problematizou a predominância dos textos de e-serviços escritos em burocratês por divergir do conceito de "orientação para as necessidades do usuário". A orientação para o usuário é um conceito basilar nos estudos sobre valor público e nas ações para reduzir a segregação digital.

Por fim, o artigo argumentou que as diretrizes de Linguagem Simples apresentam alinhamento com o fator direcionador de valor público chamado "design do e-serviço" e têm potencial para contribuir com as variáveis "facilidade de uso" e "orientação para o usuário" em serviços públicos digitais.

Desta forma, considerando que:

- E-govs devem ser "mais valiosos e usáveis" (AL-HUJRAN ET AL., 2015);

- A ONU recomenda que serviços públicos digitais estejam disponíveis "a todos, sem deixar ninguém para trás" (UNITED NATIONS, 2018, xxiii);

- $88 \%$ da população brasileira apresentam algum grau de dificuldade para elaborar textos longos e de maior complexidade;

- Textos de e-serviços são predominantemente escritos em burocratês;

- Diversos países têm experiências positivas no uso de Linguagem Simples em textos de e-gov;

é possível inferir que adotar a Linguagem Simples no e-gov brasileiro pode vir a facilitar o acesso aos e-serviços e reduzir a segregação digital.

Portanto, mostra-se oportuno avaliar o papel do estilo de linguagem na compreensibilidade textual de e-serviços, examinando aspectos linguísticos que facilitam ou dificultam a leitura.

A pesquisa na qual o presente trabalho está inserido pretende conduzir um experimento neste sentido. A investigação vem sendo desenvolvida no mestrado do programa de pós-graduação em Design na Pontifícia Universidade Católica (PUC-Rio), dentro da linha Ergonomia e Usabilidade e Interação Humano-Computador, em interseção com estudos psicolinguísticos sobre leitura e compreensibilidade textual conduzidos no Programa de Pós-Graduação 
PUC-Rio Pontifícia Universidade Católica do Rio de Janeiro Departamento de Artes \& Design | PPGDesign

LEUI | Laboratório de Ergodesign e Usabilidade de Interfaces

em Estudos da Linguagem, da mesma instituição. Trata-se de pesquisa que faz uso de metodologia qualitativa e quantitativa, com aplicação de um estudo experimental.

\section{Referências bibliográficas}

III ENCONTRO BRASILEIRO DE GOVERNO ABERTO. Painel "Só é acessível se der para entender: linguagem clara já!’. São Paulo, 5 dez.2018. Disponível em: https://governoaberto. sched.com/event/J1dM/so-e-acessivel-se-der-paraentender-linguagem-clara-ja. Acesso em: 20 fev. 2020 .

5 SEMANA DE INOVAÇÃO EM GOVERNO. Sessão Tendências em Experiência do Usuário: palestra "Textos incompreensíveis fazem mal à cidadania". Brasília, 5 nov. 2029. Disponível em: https:/semanadeinovacao.enap.gov.br/programacao/ \#1571060499440-caddd0fe-5b80. Acesso em: 20 fev. 2020.

\section{AÇÃO EDUCATIVA; INSTITUTO PAULO} MONTENEGRO. INAF Brasil 2018 - Resultados preliminares. [Ana Lima e Roberto Catelli Jr., coord.]. São Paulo: Ação Educativa e Instituto Paulo Montenegro, 2018. 22p. Disponível em:

http://acaoeducativa.org.br/wp-

content/uploads/2018/08/Inaf2018_Relat\%C3\%B3ri o-Resultados-Preliminares_v08Ago2018.pdf Acesso em: 20 fev. 2020

AL-HUJRAN, Omar; AL-DEBEI, M Mutaz M.; CHATFIELD, Akemi; MIGDADI, Mahmoud. The imperative of influencing citizen attitude toward e-government adoption and use. Computers in Human Behavior, [s.1.], 53, p.189-203, 2015.

ANDERSON, S.R. Computer Analysis of PresentDay American English by Henry Kučera, W. Nelson Francis (review). Foundations of Language, vol. 7, no. 3, p. 453-454, Agosto 1971.

BARBOZA, Elza Maria Ferraz. A linguagem clara em conteúdos de websites governamentais para promover a acessibilidade de cidadãos com baixo nível de escolaridade. Inclusão Social, Brasília, v. 4, n. 1, p. 52-66, jul/dez 2010. Disponível em: http://revista.ibict.br/inclusao/article/view/1644. Acesso em: 20 fev. 2020. BARBOZA, Elza Maria Ferraz; NUNES, Eny Marcelino de Almeida. A inteligibilidade dos websites governamentais brasileiros e o acesso para usuários com baixo nível de escolaridade. Inclusão Social, Brasília, v. 2, n. 2, p. 19-33. abril/set 2007. Disponível em: http://revista.ibict.br/inclusao/ article/view/1599. Acesso em: 20 fev. 2020.

BRASIL. Decreto de 3 de abril de 2000. Institui Grupo de Trabalho Interministerial para examinar e propor políticas, diretrizes e normas relacionadas com as novas formas eletrônicas de interação. Brasília: Presidência da República, 2000. Disponível em: http:/www.planalto.gov.br/ ccivil_03/DNN/2000/Dnn8917.htm. Acesso em: 20 fev. $20 \overline{0} 20$.

BRASIL. Decreto de 18 de outubro de 2000. Cria, no âmbito do Conselho de Governo, o Comitê Executivo do Governo Eletrônico, e dá outras providências. Brasília: Presidência da República, 2000. Disponível em: http://www.planalto.gov.br/ ccivil 03/DNN/DNN9067.htm. Acesso em: 12 set. 2019.

\section{BRASIL. Decreto no 8.638 de 15 de janeiro de}

2016. Institui a Política de Governança Digital no âmbito dos órgãos e das entidades da administração pública federal direta, autárquica e fundacional. Brasília: Presidência da República, 2016.

Disponível em: http://www.planalto.gov.br/ccivil 03/ Ato20152018/2016/Decreto/D8638.htm

Acesso em: 21 fev. 2020.

BRASIL. Lei $\mathbf{n}^{\mathbf{0}} \mathbf{1 2 . 5 2 7}$, de 18 de novembro de 2011. Regula o acesso a informações previsto no inciso XXXIII do art. $5^{\circ}$, no inciso II do $\S 3^{\circ}$ do art. 37 e no $\S 2^{\circ}$ do art. 216 da Constituição Federal; altera a Lei $n^{\circ} 8.112$, de 11 de dezembro de 1990; revoga a Lei $n^{\circ} 11.111$, de 5 de maio de 2005, e dispositivos da Lei $n^{\circ} 8.159$, de 8 de janeiro de 1991; e dá outras providências. Disponível em: http://www.planalto.gov.br/ccivil 03/ ato20112014/2011/lei/112527.htm. Acesso em: 20 fev. 2020.

BRASIL. Lei n⿳ 13.146, de 6 de julho de 2015. Institui a Lei Brasileira de Inclusão da Pessoa com Deficiência (Estatuto da Pessoa com Deficiência). Disponível em: http://www.planalto.gov.br/ccivil 03/ ato20152018/2015/lei/113146.htm

Acesso em: 21 fev. 2020.

BRASIL. Lei n⿳ 13.460, de 26 de junho de 2017. Dispõe sobre participação, proteção e defesa dos direitos do usuário dos serviços públicos da 
PUC-Rio Pontifícia Universidade Católica do Rio de Janeiro Departamento de Artes \& Design | PPGDesign

administração pública. Disponível em:

http://www.planalto.gov.br/ccivil 03/ ato20152018/2017/lei/113460.htm. Acesso em: 20 fev. 2020.

BRASIL. Lei $\mathrm{n}^{0} \mathbf{1 3 . 7 0 9}$, de 14 de agosto de 2018.

Lei Geral de Proteção de Dados Pessoais (LGPD).

Disponível em:

http://www.planalto.gov.br/ccivil_03/_ato2015-

2018/2018/lei/L13709.htm

Acesso em: 20 fev. 2020.

BRASIL. Projeto de lei 6256/2019. Institui a Política Nacional de Linguagem Simples nos órgãos e entidades da administração pública direta e indireta. Brasília, 2019. Disponível em:

https://www.camara.leg.br/proposicoesWeb/fichadet $\underline{\text { ramitacao} ? \text { idProposicao }=2231632}$

. Acesso em: 1 mar.2020

BRASIL. Escola Nacional de Administração Pública. Pesquisa sobre serviços públicos de atendimento do governo federal. Brasília: Enap, 2018. Disponível em: https://repositorio.enap. gov.br/handle/1/3217. Acesso em: 20 fev. 2020

BRASIL. Ministério do Planejamento, Desenvolvimento e Gestão. Estratégia de Governança Digital - EGD: Transformação Digital - cidadania e governo 2016-2019, versão revisada. Brasília, DF: Ministério do Planejamento, Desenvolvimento e Gestão, Secretaria de Tecnologia da Informação e Comunicação, 2018, 56 p. Disponível em:

https://www.gov.br/governodigital/pt-br/estrategiade-governanca-

digital/revisaodaestrategiadegovernancadigital20162 019.pdf

Acesso em: 1 mar. 2020.

BRASIL. Ministério do Planejamento, Desenvolvimento e Gestão. Fugindo do "burocratês": como facilitar o acesso do cidadão ao serviço público. Brasília: Ministério do Planejamento, Desenvolvimento e Gestão, 2016. 11p. Disponível em: http://www.gespublica. gov.br/sites/default/files/documentos/linguagem cid ada - versao final_web.pdf. Acesso em: 20 fev.2020.

COMITÊ GESTOR DA INTERNET NO BRASIL. TIC Governo Eletrônico 2017: Pesquisa sobre o uso das tecnologias de informação e comunicação no setor público brasileiro. São Paulo: Comitê Gestor da Internet no Brasil, 2018. Disponível em:
https://cetic.br/media/docs/publicacoes/2/TIC_eGO V_2017_livro_eletronico.pdf. Acesso em: 20 fev.2020.

CUTTS, Martin. Oxford Guide to Plain English. Oxford: Oxford University Press, 2013.

ENCONTRO INTERNACIONAL DE INOVAÇÃO EM GOVERNO. Mesa "Como a linguagem pode ajudar o governo a se relacionar melhor com a sociedade?". São Paulo, 9 ago. 2020. Disponível em: https://011lab.prefeitura.sp.gov.br/evento2019/. Acesso em: 20 fev. 2020.

FISCHER, Heloisa. Clareza em textos de e-gov, uma questão de cidadania. Rio de Janeiro: Com Clareza, 2018.

GOBBledyGOOK. Public Administration Review, vol. 4, No. 2, Spring, 1944, pp. 151-152.

GOV.BR. Adquirir repelente para gestante inscrita no Programa Bolsa Família. Última atualização 31 jul. 2019. Disponível em: https://www.gov.br/pt-br/servicos/adquirirrepelente-para-gestante-inscrita-no-programa-bolsafamilia. Acesso em: 20 fev.2020

GOWERS, E. The Complete Plain Words. Boston: David R. Godine, 1988.

HARRIS, Lynda; KLEINMAN, Susan; MOWAT, Christine. Setting Plain Language standards. The Clarity Journal, Lansing, n. 64, p.16-25, novembro 2010. Disponível em: http://www.clarityinternational.net/wp-content/uploads/2015 /05/Clarity-no-64-bookmarked1.pdf. Acesso em: 20 fev.2020.

HOUAISS, Antonio. Dicionário Houaiss da Língua Portuguesa. Rio de Janeiro: Objetiva, 2001.

JORDAN, Martin. Creating public value through service design: Facilitation of human-centred service transformation in the city-state of Hamburg. Dissertação (Mestrado em Service Innovation \& Design) - Laurea University of Applied Sciences, Vantaa, Finlândia, 2019. Disponível em: https://www.theseus.fi/handle/10024/227264.

Acesso em: 20 fev.2020. 
PUC-Rio Pontifícia Universidade Católica do Rio de Janeiro Departamento de Artes \& Design | PPGDesign

LEUI | Laboratório de Ergodesign e Usabilidade de Interfaces

KELLY, Gavin; MULGAN, Geoff; MUERS, Stephen. Creating Public Value: An analytical framework for public service reform. UK, Cabinet Office - Strategy Unit, outubro 2002. 35p.

Disponível em: https://www.academia.edu/ 23693003/Creating_Public_Value_An_analytical_fr amework_for_public_service_reform. Acesso em: 20 fev.2020.

\section{LOPES, Karen M. Gross. Fatores direcionadores} para a criação de valor público na adoção de serviços eletrônicos pelo cidadão. Dissertação (Mestrado em Administração) - Pontifícia Universidade Católica do Rio Grande do Sul, Porto Alegre, 2016. Disponível em:

http://tede2.pucrs.br/tede2/handle/tede/7216. Acesso em: 20 fev. 2020.

LOPES, Karen M.; MACADAR, Marie Anne; LUCIANO, Edimara Mezzomo.Criando valor público em serviços digitais: uma proposta de conceito. Revista Eletrônica de Gestão Organizacional - GESTÃ̃ O.ORG., v. 16, edição especial, p. 207-221, 2018. Disponível em: https://periodicos.ufpe.br/revistas/gestaoorg/article/v iew/239271/31623. Acesso em: 20 fev.2020.

. Valor público: o cidadão no centro da gestão pública. 2017 Pesquisa TIC Governo Eletrônico. São Paulo: Comitê Gestor da Internet, 2018, p. 7583. Disponível em: https://www.cetic.br/media/docs/publicacoes/2/TIC eGOV 2017 livro eletronico.pdf

Acesso em: 20 fev.2020.

MARTINS, Stefan; FILGUEIRAS, Lucia. Métodos de Avaliação de Apreensibilidade das Informações Textuais. Congreso Latinoamericano de la Interacción Humano-Computadora, [s.1.], 2007. Anais [...]. Disponível em: https://docplayer.com.br/10448464-Metodos-deavaliacao-de-apreensibilidade-das-informacoestextuais-uma-aplicacao-em-sitios-de-governoeletronico.html. Acesso em: 1 mar. 2020.

MENDONÇA, Neide Rodrigues de Souza. Desburocratização Linguística: Como simplificar textos administrativos. São Paulo: Livraria Pioneira Editora, 1987.

OECD. Revisão do Governo Digital do Brasil: Rumo à Transformação Digital do Setor Público. Principais conclusões. Projeto Governo Digital OCDE, [s.1.], 2018. Disponível em: http://editor.planejamento.gov.br/seminariodigital/se minario/digital-gov-review-brazil-portugues.pdf.

Acesso em: 1 mar. 2020.

\section{PLAIN LANGUAGE ASSOCIATION}

INTERNATIONAL. O que é linguagem clara?.

[s.d.] Disponível em:

https://plainlanguagenetwork.org/

plain-language/o-que-e-linguagem-clara/. Acesso em: 20 fev.2020.

RANA, Nripendra P.; DWIVEDI, Yogesh K. Citizen's adoption of an e-government system: Validating extended social cognitive theory (SCT). Government Information Quarterly, n. 32, p. 172-181, 2015.

SÃO PAULO (Estado). Orientações para Adoção de Linguagem Clara. São Paulo: Fundação Sistema Estadual de Análise de Dados - Seade, 2016. Disponível em: http://www.governoaberto. sp.gov.br/wp-content/uploads/2017/12/orientacoes para adocao linguagem clara ptBR.pdf. Acesso em: 20 fev.2020.

SÃO PAULO (Município). Decreto $\mathbf{n}^{0} 59.067$ de 11 de novembro de 2019. Institui o Programa Municipal de Linguagem Simples no âmbito da Administração Pública Municipal. Disponível em: http://legislacao.prefeitura.sp.gov.br/leis/decreto59067-de-11-de-novembro-de-2019. Acesso em: 20 fev.2020.

SÃO PAULO (Município). Projeto de Lei 226/2019. Institui a Política Municipal de Linguagem Clara nos órgãos da administração direta e indireta, e dá outras providências. São Paulo: Câmara Municipal, 2019. Disponível em: http://documentacao.camara.sp.gov.br/cgibin/wxis.bin/iah/scripts/?IsisScript=iah.xis\&lang=pt $\&$ format $=$ detalhado.pft\&base $=$ proje $\&$ form $=A \&$ next Action $=$ search\&indexSearch $=\wedge \mathrm{nTw}^{\wedge}$ ITodos $\% 20 \mathrm{os}$ $\% 20$ campos\&exprSearch $=\mathrm{P}=\mathrm{PL} 2262019$. Acesso em: 1 mar. 2020

SCHRIVER, Karen. Plain Language in the US Gains Momentum: 1940- 2015. IEEE Transactions on Professional Communications, vol. 60, n. 4, p. 343-383, dezembro 2017.

SILVEIRA, Maria Inês Matoso. O burocratês: análise à luz de uma gramática retórica. Revista da ABRALIN, v. 7, n. 1, p. 215-258, janeiro/junho 2008. 
UNITED NATIONS. E-Government Survey 2018:

Gearing E-Government To Support Transformation Towards Sustainable And Resilient Societies.

United Nations. New York, 2018. Disponível em:

https://www.un.org/development/desa/publications/

2018-un-e-government-survey.html

Acesso em: 20 fev.2020.
Agradecimentos

O presente trabalho foi realizado com apoio da Coordenação de Aperfeiçoamento de Pessoal de Nível Superior - Brasil (CAPES) - Código de

Financiamento 001( $1^{\mathrm{a}}$ autora); CNPq 308375/20173 ( $2^{\mathrm{a}}$ autora); CNPq 311422/2019-5 ( $3^{\mathrm{a}}$ autora). 